\title{
A comparison of different methodologies for rating definition in overhead lines
}

\author{
R. Martínez ${ }^{1}$, A. Arroyo ${ }^{1}$, M. Mañana ${ }^{1}$, P. Bernardo ${ }^{1}$, R. Mínguez $^{2}$ and R. Garrote ${ }^{2}$ \\ ${ }^{1}$ Department of Electrical and Energy Engineering \\ E.T.S.I.I.T., Cantabria University \\ Campus of Las Llamas - 39005 Santander (Spain) \\ Phone/Fax number:+0034 942 201378, e-mail: mananam@unican.es \\ ${ }^{2}$ Viesgo Distribución S.L.
}

\begin{abstract}
The grid integration of renewable energy supposes an important problem to deal with for Distributor System Operators (DSO). Distributor and transmission system operators have been using static rates for a long time to manage electric systems. Currently operators deal with one, annual, static rate or four, seasonal, static rates. This paper is devoted to the analysis of a real case of ampacity management in a $132 \mathrm{kV}$ overhead line for the purpose of stablishing new static rates based on different temporal intervals.
\end{abstract}

\section{Key words}

Ampacity, static rate, grid integration, dynamic management.

\section{Introduction}

Distributor and transmission system operators have been using static rates for a long time to manage electric systems. Static rates values are obtained from very conservative estimates of meteorological data. The most part of the operators use one or two static rates per year, only a few have stablished seasonal static rates with four values per year. With this assumption ampacity values allow to operate with a high level of security. On the other hand the increasing number of renewable generation facilities, especially those based on wind energy, greatly affects the operation of the distribution networks. In this scenario, the need to increase the capacity of the overhead lines is a major issue in order to prevent contingencies and to achieve good grid integration avoiding generation restrictions.

In technical literature there are several solutions to increase the capacity of the lines, such as dynamic management [1] [2], in which ampacity values are obtained from real time meteorological measurements. These types of solutions allow to increase lines capacity greatly. The main disadvantage of these alternatives is that security level is reduced to the minimum. An intermediate option is presented in this paper. More specific static rates are a good strategy to keep a medium security level with a considerable increase in the capacity of the lines.

In this paper is analysed different types of static rates based on distinct temporal intervals.

\section{Metodology}

The aim of this paper is to get several static rates and analyse the security level and the increase of capacity.

The line which is studied in this paper has a length of 30 $\mathrm{km}$ and a LA-280 conductor. The main characteristics of the conductor are presented in Table I.

Table II. - Conductor characteristics

\begin{tabular}{|c|c|}
\hline Type & LA-280 \\
\hline Composition & $26 / 7$ \\
\hline Diameter & $21.8 \mathrm{~mm}$ \\
\hline Static rate & $570 \mathrm{~A}$ \\
\hline Maximum temperature & $80^{\circ} \mathrm{C}$ \\
\hline
\end{tabular}

First of all, ampacity calculations are needed to define the static rates. For this propose, a monitored line is used to obtain meteorological data (wind speed, wind direction, ambient temperature and solar radiation) and subsequently these values are inputs to the ampacity calculation algorithm based on CIGRE [3] and IEEE [4] procedures. One year historical data is used for calculations. It is important to comment that meteorologists indicate that in order to obtain good statistical results a ten years historical data is recommended.

Once ampacity values are stored, it will be verified where actual static rate is placed in the real ampacity. It is 
possible to analyse if actual static rate is overestimated or underestimated.

New static rates are defined based on their temporal interval:

$\begin{array}{ll}\circ & \text { Annual } \\ \circ & \text { Biannual } \\ \circ & \text { Seasonal } \\ \circ & \text { Monthly } \\ \circ & \text { Diurnal } \\ \circ & \text { Nocturnal }\end{array}$

Annual and seasonal static rates are the most widely used by operators [5] [6] but others are interesting to be closer to the dynamic management without reducing security level to the minimum.

To determine different static rates, confidence intervals are defined to observe which are the most suitable.

Finally, new capacities and new possible transported energies are calculated.

\section{Results}

New static rates are defined through the analysis of different confidence levels. The most appropriate confidence level will depend on the operator or the criticality of the line within the network. In this paper is assumed a confidence level of $85 \%$ as minimum value of the ampacity historical data in the established period of time.

\section{ANNUAL}

In the studied line, DSO operates with an annual static rate of $570 \mathrm{~A}$. With the real-time ampacity calculations is possible to show where actual static rate is place within them. Perpendicular wind and ambient temperature are the most important parameters in ampacity calculation so it is possible to display the correlation between perpendicular wind and ambient temperature. Static rate is obtained through conservative meteorological values. In the case of this line these values are $35^{\circ} \mathrm{C}$ of ambient temperature, 0.6 $\mathrm{m} / \mathrm{s}$ of perpendicular wind and $1000 \mathrm{~W} / \mathrm{m}^{2}$ of solar radiation.

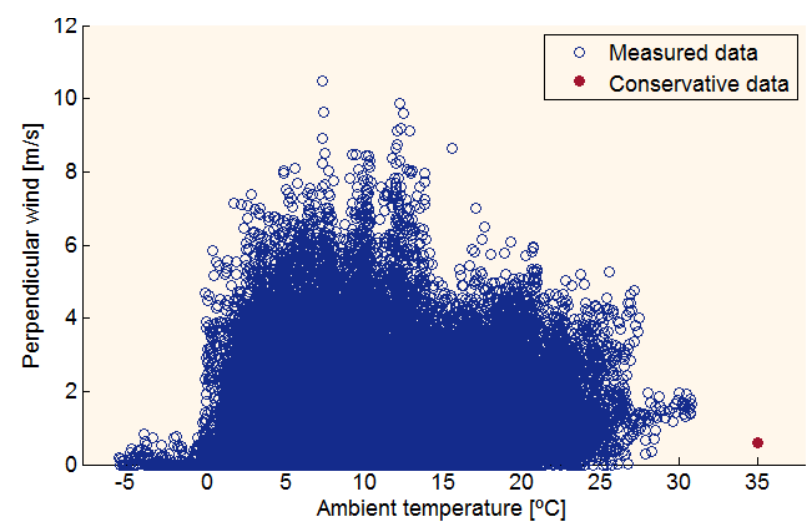

Fig. 1. Ambient temperature vs. perpendicular wind
In Fig. 1 can be observed that ambient temperature and perpendicular wind used to current static rate calculation are far from the measured data.

In Fig. 2 current static rate is represented with the realtime ampacity calculations. It is observed that static rate is conservative since only $5 \%$ of the real-time ampacity calculations are below.

New annual static rates with different confidence levels are given in Table I. Representative confidence level of $85 \%$ is marked in bold.

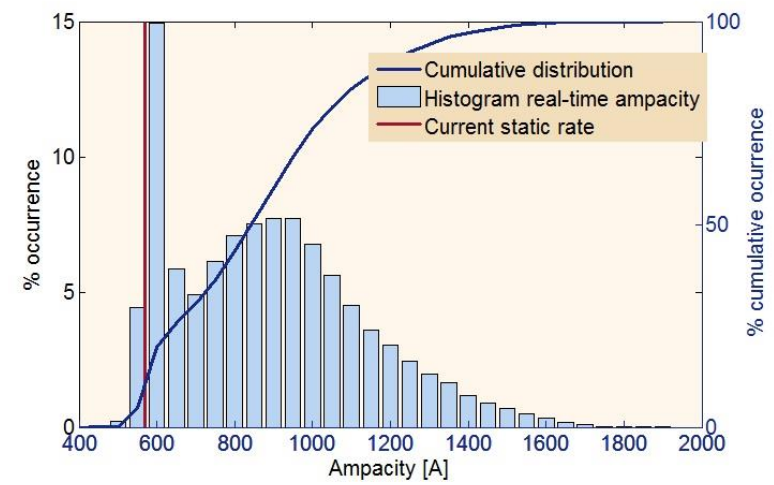

Fig. 2. Histogram of annual real-time ampacity.

Table I. - Annual static rates.

\begin{tabular}{|c|c|}
\hline Confidence level & New static rate $[\mathrm{A}]$ \\
\hline $\mathbf{1 0 0} \%$ & 448 \\
\hline $\mathbf{9 5} \%$ & 577 \\
\hline $\mathbf{9 0} \%$ & 593 \\
\hline $\mathbf{8 5} \%$ & 609 \\
\hline $\mathbf{8 0} \%$ & 627 \\
\hline $\mathbf{7 5} \%$ & 670 \\
\hline
\end{tabular}

\section{BIANNUAL}

Historical data of a year are divided in two parts. The results of the first part of the year are in Fig. 3 and Table II while second part of the year results are in Fig.4 and Table III.

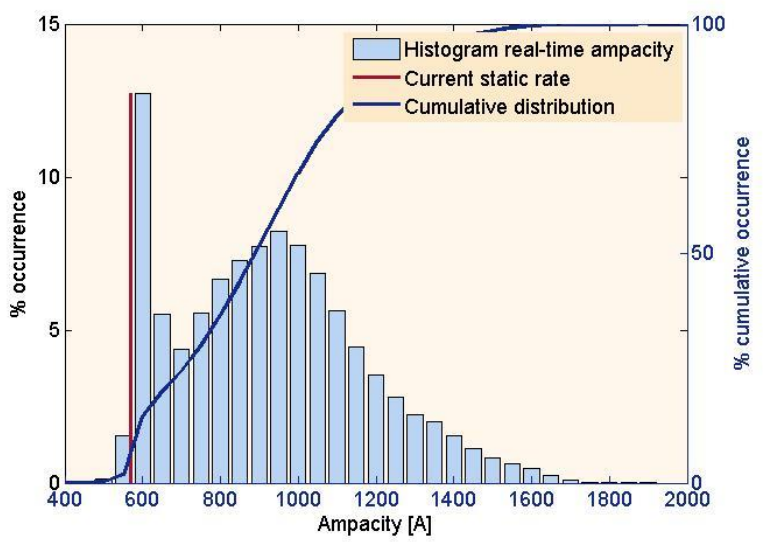

Fig. 3. Histogram of first part of the year real-time ampacity. 
Table II. - First biannual static rates.

\begin{tabular}{|c|c|}
\hline Confidence level & New static rate [A] \\
\hline $\mathbf{1 0 0} \%$ & 471 \\
\hline $\mathbf{9 5} \%$ & 592 \\
\hline $\mathbf{9 0} \%$ & 611 \\
\hline $\mathbf{8 5} \%$ & 628 \\
\hline $\mathbf{8 0} \%$ & 676 \\
\hline $\mathbf{7 5} \%$ & 732 \\
\hline
\end{tabular}

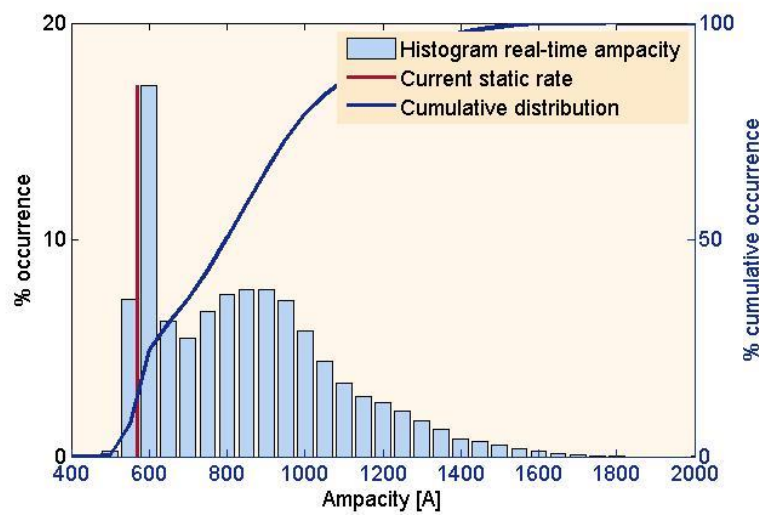

Fig. 4. Histogram of second part of the year real-time ampacity.

Table III. - Second biannual static rates.

\section{Confidence level New static rate [A]}

\begin{tabular}{|c|c|}
\hline $\mathbf{1 0 0} \%$ & 448 \\
\hline $\mathbf{9 5} \%$ & 567 \\
\hline $\mathbf{9 0} \%$ & 581 \\
\hline $\mathbf{8 5} \%$ & 593 \\
\hline $\mathbf{8 0} \%$ & 607 \\
\hline $\mathbf{7 5} \%$ & 626 \\
\hline
\end{tabular}

\section{SEASONAL}

Historical data are divided in seasons based on meteorological method (spring; March to May, summer; June to August, autumn; September to November and winter; December to February) and results are showed in Fig. 5 and Table IV, Fig. 6 and Table V, Fig. 7 and Table VI and Fig. 8 and Table VII respectively.

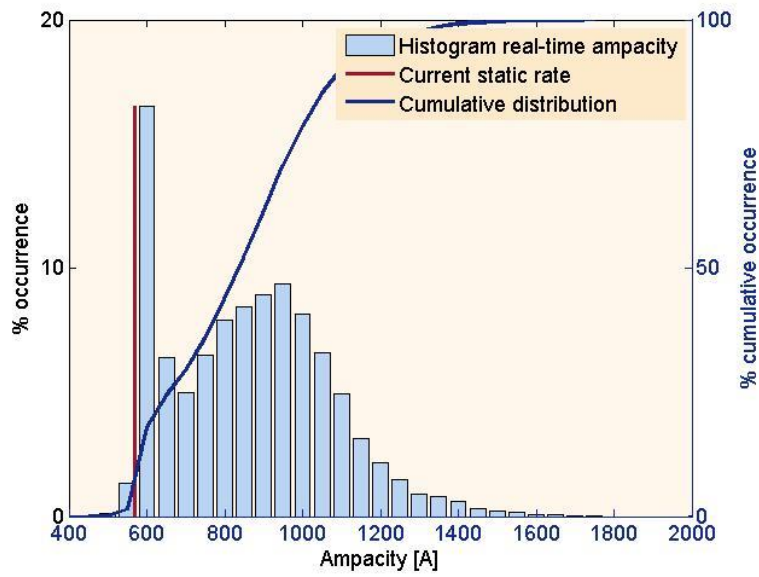

Fig. 5. Histogram of spring real-time ampacity.
Table IV. - Spring static rates.

\begin{tabular}{|c|c|}
\hline Confidence level & New static rate $[\mathbf{A}]$ \\
\hline $\mathbf{1 0 0} \%$ & 486 \\
\hline $\mathbf{9 5} \%$ & 592 \\
\hline $\mathbf{9 0} \%$ & 608 \\
\hline $\mathbf{8 5} \%$ & 618 \\
\hline $\mathbf{8 0} \%$ & 635 \\
\hline
\end{tabular}

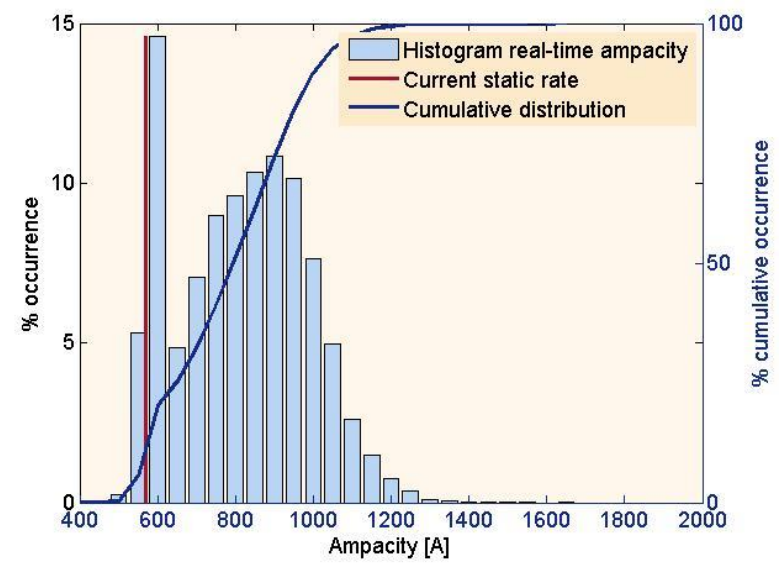

Fig. 6. Histogram of summer real-time ampacity.

Table V. - Summer static rates.

\begin{tabular}{|c|c|}
\hline Confidence level & New static rate $[\mathrm{A}]$ \\
\hline $\mathbf{1 0 0} \%$ & 448 \\
\hline $\mathbf{9 5} \%$ & 573 \\
\hline $\mathbf{9 0} \%$ & 584 \\
\hline $\mathbf{8 5} \%$ & 596 \\
\hline $\mathbf{8 0} \%$ & 623 \\
\hline $\mathbf{7 5} \%$ & 675 \\
\hline
\end{tabular}

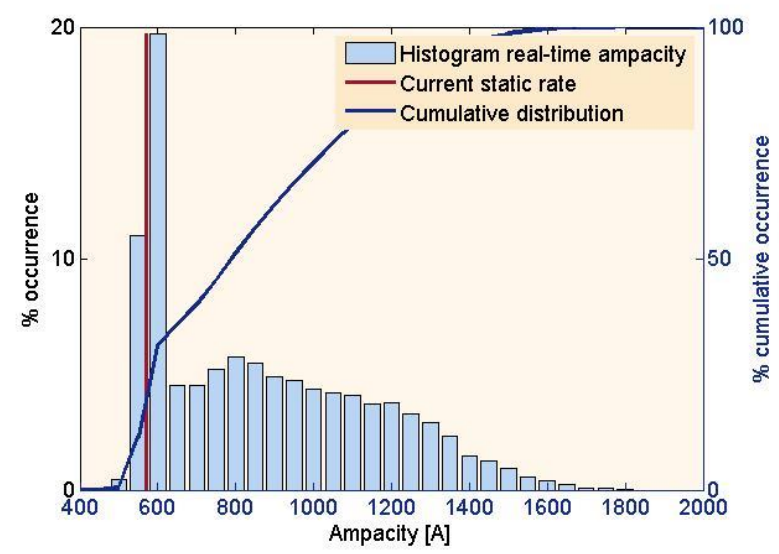

Fig. 7. Histogram of autumn real-time ampacity.

Table VI. - Autumn static rates.

\begin{tabular}{|c|c|}
\hline Confidence level & New static rate $[\mathrm{A}]$ \\
\hline $\mathbf{1 0 0} \%$ & 464 \\
\hline $\mathbf{9 5} \%$ & 561 \\
\hline $\mathbf{9 0} \%$ & 572 \\
\hline $\mathbf{8 5} \%$ & $\mathbf{5 8 2}$ \\
\hline $\mathbf{8 0} \%$ & 591 \\
\hline $\mathbf{7 5} \%$ & 600 \\
\hline
\end{tabular}




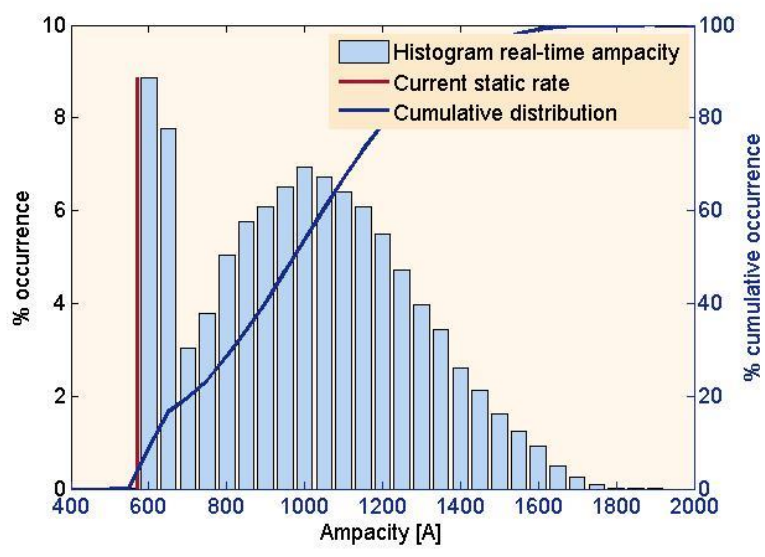

Fig. 8. Histogram of winter real-time ampacity.

Table VII. - Winter static rates.

\begin{tabular}{|c|c|}
\hline Confidence level & New static rate $[\mathbf{A}]$ \\
\hline $\mathbf{1 0 0} \%$ & 567 \\
\hline $\mathbf{9 5} \%$ & 614 \\
\hline $\mathbf{9 0} \%$ & 628 \\
\hline $\mathbf{8 5} \%$ & 656 \\
\hline $\mathbf{8 0} \%$ & 730 \\
\hline $\mathbf{7 5} \%$ & 791 \\
\hline
\end{tabular}

\section{MONTHLY}

Another interesting time interval to define new static rates is a monthly division. It is represented in Fig. 9 the histogram of the most restrictive month and in Fig. 10 the histogram of the least restrictive. In Table VIII and Table IX is showed new static rates of each month.

The most restrictive month in terms of new static rates is September and the least restrictive one is February.

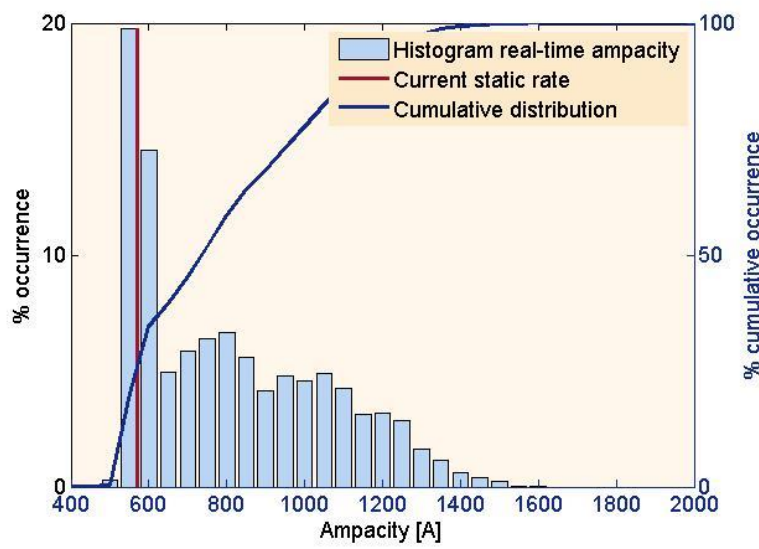

Fig. 10. Histogram of September real-time ampacity.

Table VIII. - September static rates.

\begin{tabular}{|c|c|}
\hline Confidence level & New static rate $[\mathbf{A}]$ \\
\hline $\mathbf{1 0 0} \%$ & 577 \\
\hline $\mathbf{9 5} \%$ & 693 \\
\hline $\mathbf{9 0} \%$ & 813 \\
\hline $\mathbf{8 5} \%$ & $\mathbf{8 7 7}$ \\
\hline $\mathbf{7 5} \%$ & 938 \\
\hline
\end{tabular}

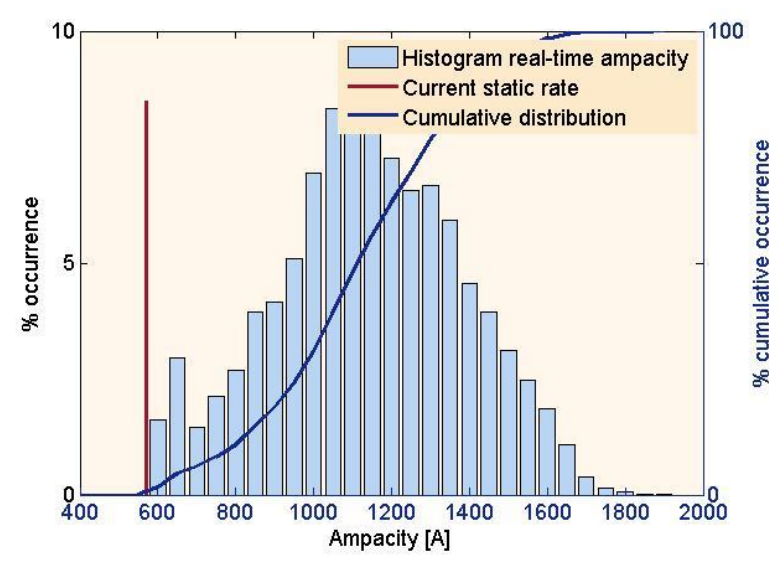

Fig. 10. Histogram of February real-time ampacity.

Table IX. - February static rates.

\begin{tabular}{|c|c|}
\hline Confidence level & New static rate $[\mathrm{A}]$ \\
\hline $\mathbf{1 0 0} \%$ & 464 \\
\hline $\mathbf{9 5} \%$ & 558 \\
\hline $\mathbf{9 0} \%$ & 564 \\
\hline $\mathbf{8 5} \%$ & 569 \\
\hline $\mathbf{8 0} \%$ & 575 \\
\hline $\mathbf{7 5} \%$ & 585 \\
\hline
\end{tabular}

\section{DIURNAL AND NOCTURNAL}

Meteorological parameters as ambient temperature and wind are very stable during the night when solar radiation is zero. In these conditions ampacity varies little so it can be interesting to distinguish between day and night in annual rate.

Results of diurnal are shown in Fig. 11 and Table X while nocturnal new rates are in Fig. 12 and Table XI.

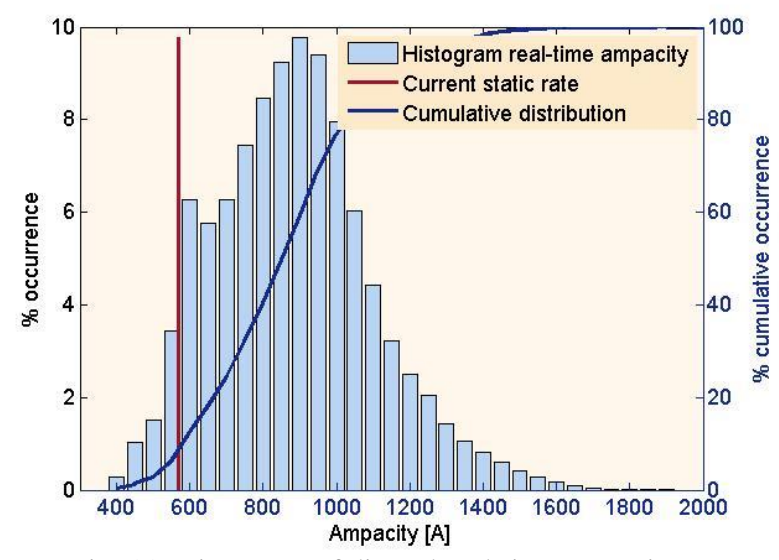

Fig. 11. Histogram of diurnal real-time ampacity.

Table X. - Diurnal static rates.

\begin{tabular}{|c|c|}
\hline Confidence level & New static rate $[\mathrm{A}]$ \\
\hline $\mathbf{1 0 0} \%$ & 230 \\
\hline $\mathbf{9 5} \%$ & 564 \\
\hline $\mathbf{9 0} \%$ & 605 \\
\hline $\mathbf{8 5} \%$ & 646 \\
\hline $\mathbf{8 0} \%$ & 690 \\
\hline $\mathbf{7 5} \%$ & 729 \\
\hline
\end{tabular}




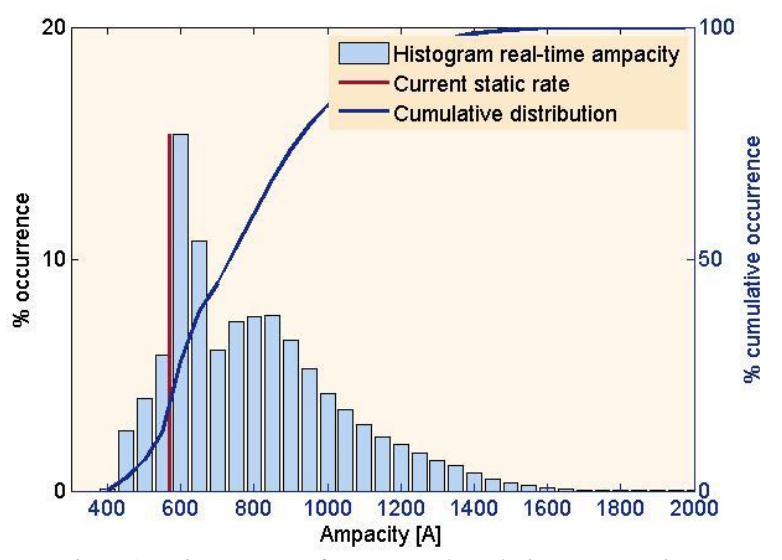

Fig. 12. Histogram of nocturnal real-time ampacity.

Table XI. - Nocturnal static rates.

\begin{tabular}{|c|c|}
\hline Confidence level & New static rate $[\mathbf{A}]$ \\
\hline $\mathbf{1 0 0} \%$ & 392 \\
\hline $\mathbf{9 5} \%$ & 502 \\
\hline $\mathbf{9 0} \%$ & 564 \\
\hline $\mathbf{8 5} \%$ & $\mathbf{5 8 3}$ \\
\hline $\mathbf{8 0} \%$ & 599 \\
\hline $\mathbf{7 5} \%$ & 615 \\
\hline
\end{tabular}

\section{Conclusion}

In conclusion, with temporal divisions in the static rates of the line and with a confidence level of $85 \%$ is possible to obtain, in most cases, an increase in static rates.

Furthermore, it is interesting that, in most cases, current static rate is above $100 \%$ confidence level static rate, consequently, current static rate is not completely safe.

Annual rate increases 39 A of ampacity, so the capacity of the line would improve in $9 \mathrm{MW}$. When diurnal and nocturnal analysis is implemented 10 additional MW are achieved in diurnal case and $2 \mathrm{MW}$ in nocturnal one.

In biannual case 13 additional MW are achieved in the most favourable case and 3 additional MW in the least favourable one.

Applying seasonal static rates an increase of $11 \mathrm{MW}$ is achieved winter. Theoretically, it is expected that summer will be the most restrictive season but in practice autumn has the lowest static rate.

Monthly analysis characterise September as the most favourable month regarding ampacity with 40 additional MW. On the other hand, February is the most restrictive month with $0.1 \mathrm{MW}$ less.

\section{Acknowledgement}

This work was supported by the Spanish Government under the $\mathrm{R}+\mathrm{D}$ initiative INNPACTO with reference IPT2011-1447-920000 and Spanish R+D initiative with reference ENE2013-42720-R.

The authors would also like to acknowledge Viesgo for its support.

\section{References}

[1] A. Madrazo, A. González, R. Martínez, M. Mañana, E. Hervás, A. Arroyo, P.B. Castro, D. Silió. "Increasing Grid Integration of Wind Energy by Using Ampacity Techniques." International Conference on Renewable Energies and Power Quality 2013, Bilbao.

[2] A. Madrazo, A. González, R. Martínez, R. Domingo, M. Mañana, A. Arroyo, P.B. Castro, D. Silió and R. Lecuna. "Analysis of a real case of ampacity management in a $132 \mathrm{kV}$ network integrating high rates of wind energy." International Conference on Renewable Energies and Power Quality 2015, La Coruña.

[3] "TB601 Guide for Thermal Rating Calculations of Overhead Lines”, CIGRE, Working Group B2.43, Dec. 2014.

[4] "IEEE Standard for Calculating the Current-Temperature Relationship of Bare Overhead Conductors," in IEEE Std 7382012 (Revision of IEEE Std 738-2006 - Incorporates IEEE Std 738-2012 Cor 1-2013), vol., no., pp.1-72, Dec. 232013.

[5] Xiaolong Hu; Cotton, I., "Impact of climate change on static ratings of overhead line in Edinburgh," in Power Engineering Conference (UPEC), 2013 48th International Universities', vol., no., pp.1-6, 2-5 Sept. 2013.

[6] Heckenbergerova, J.; Musilek, P.; Filimonenkov, K., "Assessment of seasonal static thermal ratings of overhead transmission conductors," in Power and Energy Society General Meeting, 2011 IEEE, vol., no., pp.1-8, 24-29 July 2011 